\title{
Addition of gonadotropin releasing hormone agonist for luteal phase support in in-vitro fertilization: an analysis of 2739 cycles
}

\author{
Erhan Şimşek ${ }^{1}$, Esra Bulgan Kılıçdağ ${ }^{1}$, Pınar Çağlar Aytaçl, Gonca Çoban ${ }^{1}$, Seda Yüksel Şimşek ${ }^{2}$, Tayfun Çok ${ }^{1}$, Bülent \\ Haydardedeoğlu ${ }^{1}$ \\ 'Department of Obstetrics and Gynecology, Division of Reproductive Endocrinology and IVF Unit, Başkent University Faculty \\ of Medicine Adana Hospital, Adana, Turkey \\ ${ }^{2}$ Department of Obstetrics and Gynecology, Adana Maternity Hospital, Adana, Turkey
}

\section{Abstract}

Objective: Luteal phase is defective in in vitro fertilization (IVF) cycles, and many regimens were tried for the very best luteal phase support (LPS). Gonadotropin releasing hormone (GnRH) agonist use, which was administered as an adjunct to the luteal phase support in IVF cycles, was suggested to improve pregnancy outcome measures in certain randomized studies. We analyzed the effects of addition of GnRH agonist to standard progesterone luteal support on pregnancy outcome measures, particularly the live birth rates.

Material and Methods: This is a retrospective cohort study, including 2739 IVF cycles. Long GnRH agonist and antagonist stimulation IVF cycles with cleavage-stage embryo transfer were included. Cycles were divided into two groups: Group A included cycles with single-dose GnRH agonist plus progesterone LPS and Group B included progesterone only LPS. Live birth rates were the primary outcome measures of the analysis. Miscarriage rates and multiple pregnancy rates were the secondary outcome measures.

Results: Live birth rates were not statistically different in GnRH agonist plus progesterone (Group A) and progesterone only (Group B) groups in both the long agonist and antagonist stimulation arms (40.8\%/41.2\% and 32.8\%/34.4\%, p<0.05 respectively). Moreover, pregnancy rates, implantation rates, and miscarriage rates were found to be similar between groups. Multiple pregnancy rates in antagonist cycles were significantly higher in Group A than those in Group B (12.0\% and 6.9\%, respectively).

Conclusion: A beneficial effect of a single dose of GnRH agonist administration as a luteal phase supporting agent is yet to be determined because of the wide heterogeneity of data present in literature. Well-designed randomized clinical studies are required to clarify any effect of luteal GnRH agonist addition on pregnancy outcome measures with different doses, timing, and administration routes of GnRH agonists. (J Turk Ger Gynecol Assoc 2015; 16: 96-101)

Keywords: GnRH agonist, luteal phase support, in vitro fertilization (IVF), progesterone

Received: 23 February, 2015

Accepted: 06 April, 2015

\section{Introduction}

In the current controlled ovarian hyperstimulation $(\mathrm{COH})$ cycle management, gonadotrophin releasing hormone (GnRH) agonists or gonadotrophin releasing hormone antagonists are indispensable agents for the prevention of premature luteinization with acceptable live birth rates (1-3). However, supraphysiological steroid hormone levels together with the suppressed luteinizing hormone (LH) levels by both $\mathrm{GnRH}$ agonist and GnRH antagonist administration during $\mathrm{COH}$ cycles lead to a defect in the luteal phase, particularly in in vitro fertilization (IVF) cycles (3-8). Therefore, use of medication for luteal phase support (LPS) has been considered to be mandatory to ensure intact corpus luteum function and to avoid any decrease in implantation and pregnancy rates (7, 9). There is still controversy over the best LPS agent and pro- tocol and its dose and duration as well as the time of initiation and cessation (10). Intravaginal or intramuscular progesterone application has become the routine practice to support luteal phase in $\mathrm{COH}$ cycles over the years either alone or in combination with estradiol $(7,11,12)$. However, there is still a search to provide optimal luteal support for better pregnancy outcome rates in $\mathrm{COH}$ cycles.

In recent years, the beneficial effects of single or repeated doses of GnRH agonist for luteal phase support were considered in different studies. GnRH agonist luteal support was hypothesized to support luteal phase by various mechanisms. Augmentation of the corpus luteum function by increasing LH secretion by the pituitary cells, direct stimulation of endometrial local GnRH receptors, and potential direct stimulation effect of GnRH agonist on the embryo, which was evidenced by increased beta human chorionic gonadotropin $(\beta-\mathrm{hCG})$ 
secretion were some of the proposed potential mechanisms of actions $(13,14)$.

The purpose of this study was to evaluate whether the addition of single-dose GnRH agonist to the progesterone for luteal support in IVF cycles improves the pregnancy outcome measures, particularly the live birth rates.

\section{Material and Methods}

\section{Study design and study population}

This study was a retrospective study conducted at Başkent University, Obstetrics and Gynecology Department Infertility and IVF Unit, from January 2006 to October 2013. Başkent University Institutional Review Board approved this study (project number: KA 12/57).

The inclusion criteria were as follows:

Couples undergoing IVF with their own gametes

Women below 40 years of age and follicle stimulating hormone (FSH) $<10$ IU

First two IVF cycles with long GnRH agonist or GnRH antagonist cycles with fresh embryo transfers

Couples having at least one grade 1 embryo available for transfer Cleavage state embryo transfer [Day 3 embryo transfer after intracytoplasmic sperm injection (ICSI) IVF cycles with luteal phase support with intravaginal or intramuscular progesterone alone or in combination with triptorelin acetate (GnRH agonist)]

Ovarian stimulation and Assisted Reproductive Techniques (ART) In the long GnRH agonist group, ovarian down-regulation was initiated with either daily $1 \mathrm{mg}$ leuprolide acetate (Lucrin, Abbott $\mathrm{GmbH}$ ) or $0.1 \mathrm{mg}$ triptorelin (Decapeptyl, Ferring $\mathrm{GmbH}$ ) that was commenced on Day 21 of the preceding menstrual bleeding. After ovarian suppression was achieved, the dose was reduced by half until the day of administering hCG. If there were no follicle cysts beyond $2 \mathrm{~cm}$ and the estradiol was $<50$ $\mathrm{pg} / \mathrm{mL}, 150-300$ IU gonadotropin stimulation with recombinant FSH (rFSH) (Puregon, MSD, the Netherlands) and rFSH (Gonal F, Merck Serono GmbH, Greece) or human menopausal gonadotropin (hMG) (Menogon, Ferring GmbH, Germany) was initiated with estradiol monitoring starting on the fifth day of stimulation. Ultrasound and blood estradiol and progesterone levels were continuously monitored until the day of ovulation induction with hCG, providing the criteria with three or more follicles that were of a diameter $>17 \mathrm{~mm}$.

In the GnRH antagonist group, gonadotropin stimulation with 150-300 IU of gonadotropins rFSH (Puregon, MSD $\mathrm{GmbH}$ ), (Gonal F, Merck Serono GmbH) or hMG (Menogon, Ferring $\mathrm{GmbH}$ ) was initiated on Day 3 of menstruation. Fixed GnRH antagonist protocol was performed by daily subcutaneously administering $0.25 \mathrm{mg}$ ganirelix (Orgalutran, Organon, the Netherlands), which was commenced on the sixth day of stimulation. Blood progesterone and estradiol and progesterone levels were monitored until the day of ovulation induction by hCG. The criteria for ovulation induction were similar to the agonist stimulation cycles with three or more follicles $>17 \mathrm{~mm}$. Oocyte retrieval was performed 35-36 h after administering 10,000 IU
hCG (Pregnyl, Organon Turkey) or $250 \mathrm{mg}$ recombinant hCG (rhCG) (Ovitrelle, Merck Serono, Italy) under transvaginal ultrasonography guidance. The 17-gauge single-lumen needles were used for oocyte retrieval under sedation with propofol (propofol 1\% Fresenius $\mathrm{Kabi}^{\mathrm{R}}$ ). Routine ICSI was performed for every case after 2-2.5 h of incubation. Embryos were transferred at the cleavage stage, three days after ICSI.

\section{Luteal phase support}

Progesterone was the routine luteal support agent, and patients had luteal support either in the form of $90 \mathrm{mg}$ intravaginal progesterone (Crinone $8 \%$ gel, Merck Serono $\mathrm{GmbH}$ ) or 50 mg intramuscular progesterone (Progynex ampule, FARMACO $\mathrm{GmbH}$ ). Progesterone support was commenced after the day of oocyte pick-up and continued until 10 completed weeks of pregnancy. In the GnRH agonist luteal support group, patients also received an additional single dose of $0.1 \mathrm{mg} \mathrm{GnRH}$ agonist namely, triptorelin (Decapeptyl Ferring $\mathrm{GmbH}$ ) three days after the transfer (six days after ICSI). Pregnancy was defined as positive for hCG on detection of above $10 \mathrm{IU} / \mathrm{mL}, 12$ days after the embryo transfer. Implantation rate was individually calculated for each woman as the number of gestational sac divided by the number of transferred embryos multiplied by 100 . Presence of at least one gestational sac was defined as clinical pregnancy with fetal cardiac activity that was detectable by transvaginal ultrasound scans. Live birth rate was the birth of a viable fetus beyond 24 weeks of gestation.

\section{Statistical analysis}

Data, which were shown to evenly distribute, were expressed as means $\pm \mathrm{SD}$. The baseline differences between the two groups were analyzed by independent t-test or one-way ANOVA test. The parameters with uneven distribution were expressed as median and minimum maximum values. The differences between the two groups were evaluated by Mann-Whitney $U$ test. In contingency tables, the $\chi^{2}$ test or the two-sided Fisher's exact test was performed. A value of $\mathrm{p}<0.05$ was considered statistically significant. SPSS 20.0 for Windows was used for data analysis version 20.0 (SPSS Inc. IBM, Chicago, IL, USA).

\section{Results}

Among 9470 IVF cycles, a total of 2739 IVF cycles, which met the inclusion criteria, were included in the analysis (Figure 1). Baseline characteristics of the patients were presented in Table 1. The mean age of patients, body mass index (BMI), and Day 3 FSH levels and antral follicle count were similar between the groups. Cycle characteristics were listed in Table 2. Days of stimulation, retrieved oocytes and metaphase II oocytes numbers, estradiol levels, and endometrial thickness at the day of ovulation trigger were found to be similar. Grade 1 embryo number and the number of transferred embryos were found to be significantly high in progesterone only luteal support group in long agonist stimulation arm, and on the contrary, these values were found to be significantly low in the antagonist stimulation arm. As we investigate the main outcome measures, live birth rates were not found to be statistically different in $\mathrm{GnRH}$ agonist 


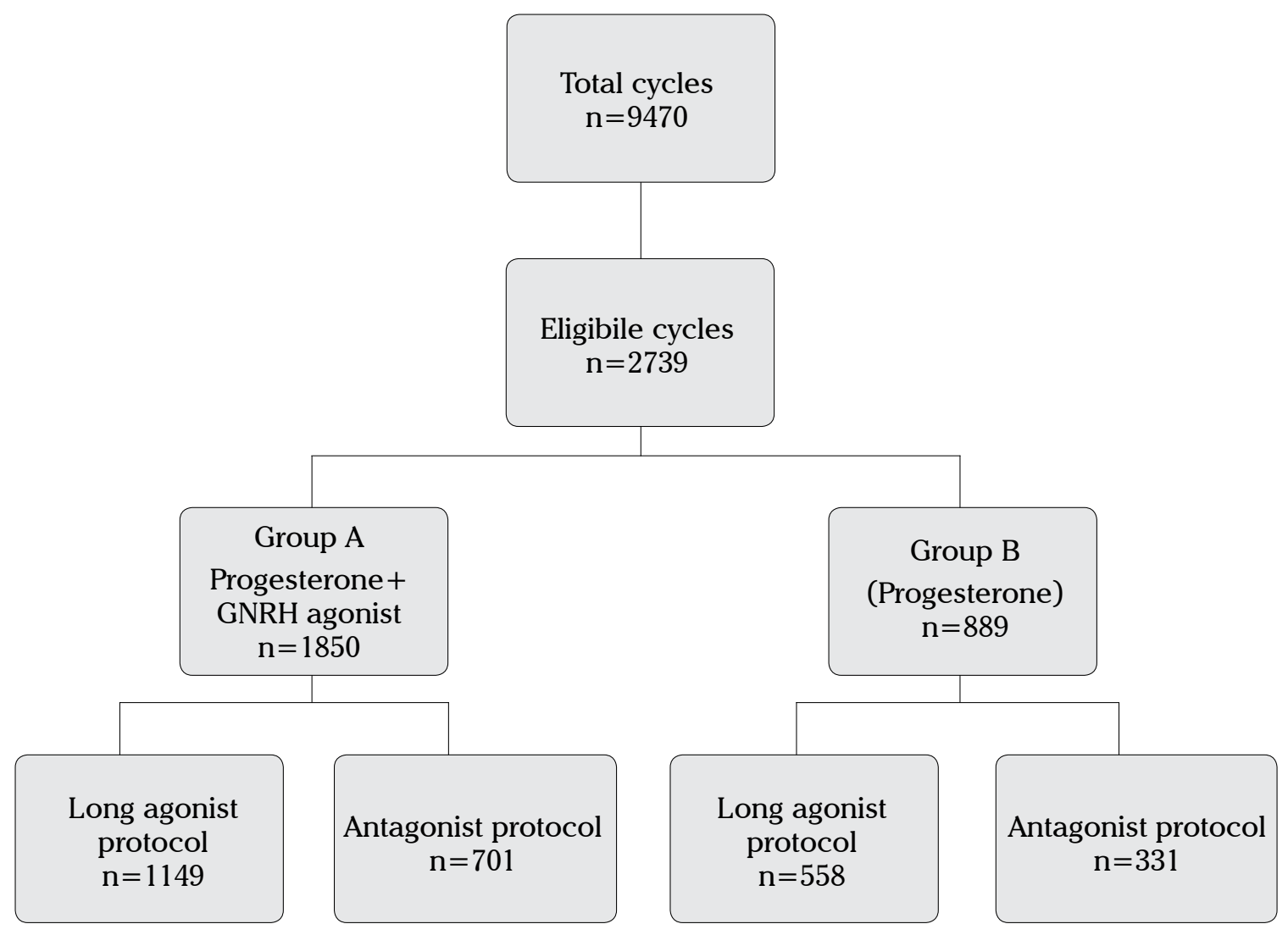

Figure 1. Flowchart of cycle distribution between groups

plus progesterone (Group A) and progesterone only group (Group B) in both the long agonist and antagonist stimulation arms (40.8\%/41.2\% and 32.8\%/34.4\%, respectively). Moreover, pregnancy, implantation, and miscarriage rates were found to be similar between the groups (Table 3). However, because the number of embryos transferred between groups was different, we stratified patients according to the number of embryos transferred. Live birth rates according to the number of transferred embryo were similar between the groups (Table 4). In contrast, stratification of live birth rates according to the number of transferred Grade I embryo (one, two, or three or more grade I embryo transfer) revealed similar results with no significant difference between the treatment groups (Table 5). Regression analysis demonstrated that age, antral follicle count, the number of metaphase II oocyte, the number of grade I embryo, and the transferred embryo significantly affected live birth rates. Luteal GnRH agonist addition showed no effect on regression analysis $(p=0.48)$.

\section{Discussion}

The administration of $\mathrm{GnRH}$ agonist in the luteal phase was initially studied as a means of contraception with unsatisfactory results (15). It was observed that unintentional or accidental
GnRH agonist administration in the luteal phase of IVF treatment cycles with pregnancies did not compromise the continuation of pregnancy but was observed to support implantation in initial reports (16-19). Although well-defined mechanisms by which $\mathrm{GnRH}$ agonist addition improves luteal support are lacking, presumptive effect at multiple levels were proposed. Direct release of $\mathrm{LH}$ by gonadotrophs was tested by Pirard et al. (20) and Tesarik et al. (14). Both Tesarik et al. (14) and Pirard et al. (20) found increased estradiol and progesterone levels during the luteal phase of GnRH agonist added cycles; however, the source and mechanisms of this increase were unclear. Furthermore, Tesarik et al. (21) reported increased hCG secretion in pregnancies with GnRH agonist luteal phase support. Authors also hypothesized a direct beneficial effect on implanting embryo (21), and increased levels of hCG in GnRH agonist luteal phase support pregnancies were observed (14). Moreover, authors suggested a direct stimulatory effect via GnRH receptors on the corpus luteum function (14).

Tesarik et al. (21) reported a pilot study in donation cycles, and Pirard et al. (13) in intrauterine insemination cycles investigated the role of GnRH agonist as a luteal support agent. The same authors Tesarik et al. (14) reported a randomized study in both the agonist and antagonist stimulated IVF-ICSI cycles with the addition of $0.1 \mathrm{mg}$ triptorelin to luteal support with beneficial 
Table 1. Patients' characteristics of the study group

\begin{tabular}{|c|c|c|c|c|}
\hline & & Group A & Group B & $\begin{array}{c}P \\
\text { value }\end{array}$ \\
\hline \multirow[t]{2}{*}{ Age } & L agonist & $30.72 \pm 4.47$ & $30.42 \pm 4.51$ & 0.19 \\
\hline & Antagonist & $31.04 \pm 4.69$ & $31.00 \pm 4.67$ & 0.89 \\
\hline \multirow[t]{2}{*}{ BMI } & L agonist & $25.34 \pm 4.18$ & $25.46 \pm 3.92$ & 0.79 \\
\hline & Antagonist & $24.89 \pm 4.21$ & $25.01 \pm 4.27$ & 0.23 \\
\hline \multirow{2}{*}{$\begin{array}{l}\text { Duration of } \\
\text { infertility (years) }\end{array}$} & L agonist & $6.0(0.6-22)$ & $7.0(1-22)$ & 0.01 \\
\hline & Antagonist & $5.0(1-26)$ & $4.5(1-20)$ & 0.02 \\
\hline \multirow{2}{*}{$\begin{array}{l}\text { Antral follicle } \\
\text { count }\end{array}$} & L agonist & $6.13 \pm 2.08$ & $5.98 \pm 2.22$ & 0.24 \\
\hline & Antagonist & $5.06 \pm 2.27$ & $5.14 \pm 2.28$ & 0.14 \\
\hline \multirow[t]{2}{*}{ Basal FSH } & L agonist & $5.89 \pm 1.79$ & $5.94 \pm 1.99$ & 0.62 \\
\hline & Antagonist & $5.97 \pm 1.85$ & $5.83 \pm 1.79$ & 0.54 \\
\hline \multicolumn{5}{|c|}{$\begin{array}{l}\text { Group A: GnRH agonist+progesterone luteal support, Group B: Progesterone only } \\
\text { luteal support. } \\
\text { Values=mean } \pm 2 \text { SD or Median (minimum-maximum). } \\
\text { BMI: body mass index; FSH: follicle stimulating hormone }\end{array}$} \\
\hline
\end{tabular}

Table 2. Cycle Characteristics of the study group

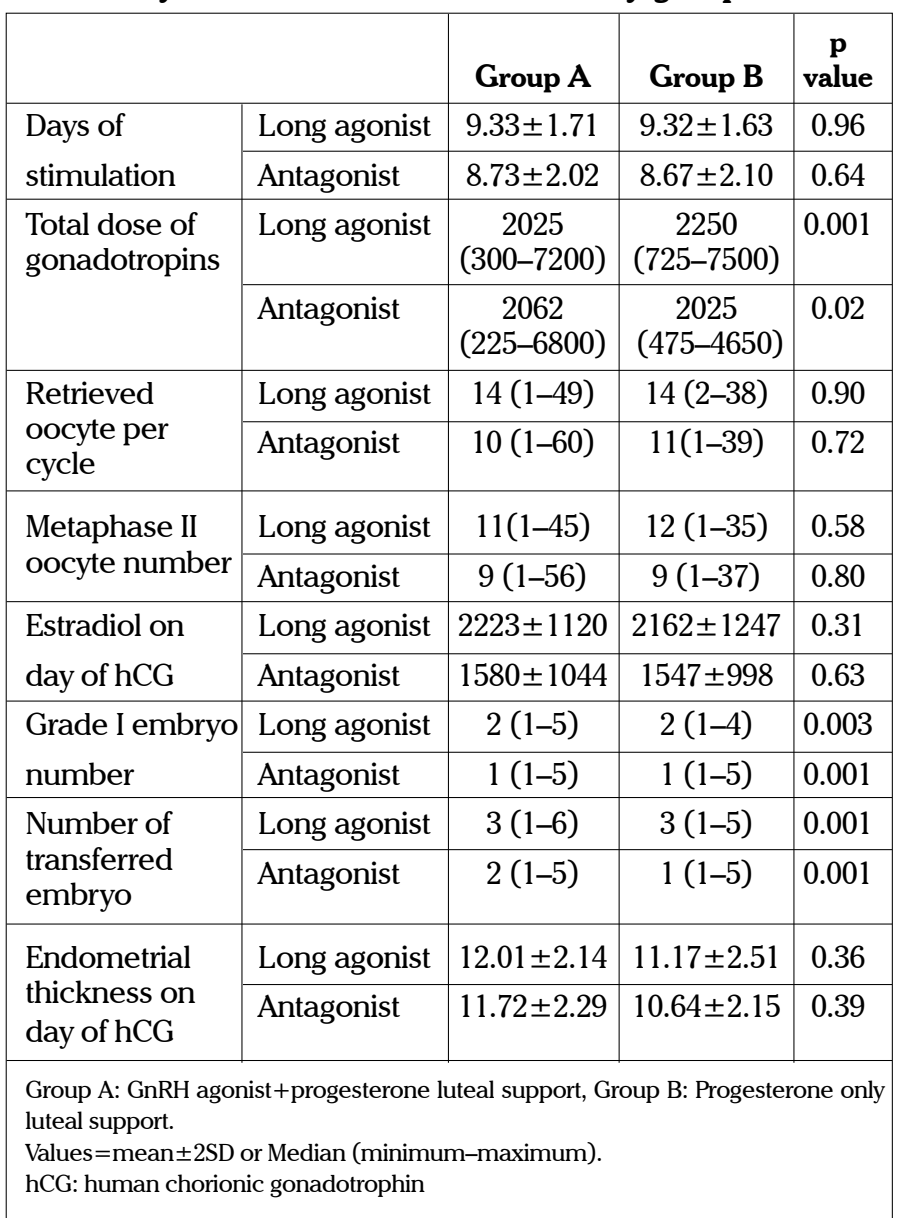

effects on pregnancy outcomes. Pirard et al. (20) studied different doses of intranasal buserelin in intrauterine insemination and IVF cycles $(13,20)$. Both of Pirard et al. $(13,20)$ studies were pilot studies with very small number of patients (24 and 23 patients in each); therefore, the pregnancy outcomes of the
Table 3. Comparison of pregnancy outcome measures

\begin{tabular}{|l|l|c|c|c|}
\hline \multicolumn{2}{|c|}{} & Group A & Group B & $\begin{array}{c}\text { p } \\
\text { value }\end{array}$ \\
\hline $\begin{array}{l}\text { Pregnancy } \\
\text { rate, n (\%) }\end{array}$ & Long agonist & $758(66.0)$ & $343(61.5)$ & 0.68 \\
\cline { 2 - 5 } & Antagonist & $377(53.8)$ & $179(54.1)$ & 0.92 \\
\hline $\begin{array}{l}\text { Implantation } \\
\text { rate, (\%) }\end{array}$ & Long agonist & $33(0-100)$ & $33(0-100)$ & 0.17 \\
\cline { 2 - 5 } & Antagonist & $33(0-100)$ & $33(0-100)$ & 0.45 \\
\hline $\begin{array}{l}\text { Miscarriage } \\
\text { rate, n (\%) }\end{array}$ & Long agonist & $193(16.8)$ & $61(10.9)$ & 0.001 \\
\cline { 2 - 5 } $\begin{array}{l}\text { Multiple pregnancy } \\
\text { rate, n (\%) }\end{array}$ & Antagonist & $85(12.1)$ & $48(14.5)$ & 0.28 \\
\cline { 2 - 5 } & Antagonist & $84(12.0)$ & $23(6.9)$ & 0.01 \\
\hline $\begin{array}{l}\text { Live birth } \\
\text { rate, } n(\%)\end{array}$ & Long agonist & $469(40.8)$ & $230(41.2)$ & 0.87 \\
\cline { 2 - 5 } & Antagonist & $230(32.8)$ & $114(34.4)$ & 0.60 \\
\hline $\begin{array}{l}\text { Group A: GnRH agonist+progesterone luteal support, Group B: Progesterone only } \\
\text { luteal support. } \\
\text { Values=mean } \pm 2 S D \text { or Median (minimum-maximum). }\end{array}$ & $279(24.3)$ & $137(24.6)$ & 0.90 \\
\hline
\end{tabular}

effect of GnRH addition to LPS agents were not possible to generalize. In the year 2009, Isik et al. (22) reported a study in which patients were blindly randomized to the addition of single-dose $0.5 \mathrm{mg}$ leuprolide acetate or hCG plus progesterone groups (22). Implantation rate and live birth rates were reported to be significantly improved by GnRH agonist addition ( $26.5 \%$ vs. $9.3 \%$ and $35.1 \%$ vs. $16.3 \%$, respectively).

There are a considerable number of studies reporting against the improvement of pregnancy outcomes with GnRH analog addition to luteal phase support. One of the largest reported randomized trials with placebo control was published by Ata et al. (6) that included 570 patients in long agonist IVF stimulation cycles. The effect of the addition of a single dose of $0.1 \mathrm{mg}$ triptorellin injection was not found to be superior over standard uniform intravaginal progesterone luteal phase support treatment (6). In the year 2010, the same authors investigated the role of GnRH agonist addition in the antagonist stimulated IVF cycles with the same study design demonstrating no beneficial effects of GnRH agonist addition on pregnancy outcomes (23). Isikoglu et al. (24) investigated the role of luteal GnRH analog in a different manner by extension of GnRHa administration until 12 days after embryo transfer in long agonist IVF-ICSI cycles. Authors did not report any significant improvement of implantation, clinical pregnancy, and live birth rates after randomization of 180 patients (24). Most recently, Ylldız et al. (25) in their randomized study failed to demonstrate significant improvement of pregnancy outcomes by single or double dose of GnRH agonist addition to progesterone and estradiol luteal support (25). There are two meta-analyses focusing on GnRH agonist addition to LPS $(26,27)$. Oliveira et al. (26) included five and Kyrou et al. (27) included six randomized studies, four of which were common to both meta-analyses (Tesarik 2006, Ata 2008, Isik 2009, Razieh 2009). While Oliveira et al. (26) concluded that GnRH agonist addition increased implantation rates, clinical pregnancy rates were found to be increased only in antagonist cycles. In the more recent meta-analysis by Kyrou et al. (27), LPS with GnRH agonist was shown to significantly increase 
Table 4. Live Birth Rates according to the number of transferred embryo

\begin{tabular}{|l|l|c|c|c|}
\hline \multicolumn{2}{|l|}{ Number of transferred embryo } & Group A & Group B & $\begin{array}{c}\text { p } \\
\text { value }\end{array}$ \\
\hline \multirow{2}{*}{ 1 embryo, n (\%) } & Long agonist & $56(31.6)$ & $18(28.1)$ & 0.60 \\
\cline { 2 - 5 } & Antagonist & $92(33.6)$ & $60(32.1)$ & 0.73 \\
\hline \multirow{2}{*}{ embryos, n (\%) } & Long agonist & $63(36.2)$ & $18(31.0)$ & 0.47 \\
\cline { 2 - 5 } & Antagonist & $67(30.2)$ & $46(36.5)$ & 0.22 \\
\hline \multirow{2}{*}{$\begin{array}{l}\text { 3 or more } \\
\text { embryos, n (\%) }\end{array}$} & Long agonist & $350(43.9)$ & $194(44.5)$ & 0.84 \\
\cline { 2 - 5 } & Antagonist & $71(34.6)$ & $8(44.4)$ & 0.40 \\
\hline
\end{tabular}

Group A: GnRH agonist+progesterone luteal support, Group B: Progesterone only luteal support.

live birth rate (27). However, heterogeneity of data were prominent because of different agents used for luteal phase support, including various combinations of progesterone, estradiol, and hCG, among the studies [Tesarik et al. (14): vaginal micronized progesterone $+\mathrm{r}-\mathrm{hCG}$ (single dose) +estradiol valerate; Ata et al. (6): Vaginal progesterone gel; Isik et al. (22): vaginal micronized progesterone + single-dose hCG; Isikoglu et al. (24): intramuscular progesterone; Razieh et al. (29): intravaginal progesterone; Fuji et al. (30): dydrogesterone+hCG) $(6,14,22,28-30)$. Therefore, luteal phase support regimens were not uniform.

Furthermore, in the meta-analysis and in different randomized studies, different doses, types and application route, and repeated doses of GnRHa were used, which would most probably cause considerable amount of heterogeneity of data and concerns of data interpretation [Fuji et al. (30): Buserelin 14 days after egg retrieval; Tesarik et al. (14): single-dose triptorelin; Ata et al. (6): $0.1 \mathrm{mg}$ single-dose triptorelin; Isik et al. (22): single-dose $0.5 \mathrm{mg}$ leuprolid; Isikoglu et al. (24): GnRHa 14 days after egg retrieval; Razieh et al. (29); single-dose $0.1 \mathrm{mg}$ triptorelin; Ylldiz et al. (25): single or double doses of $1 \mathrm{mg}$ leuprolid]. All the aforementioned heterogeneities preclude drawing firm conclusions for the beneficial effects of GnRH agonist on reproductive outcome. Although our data was retrospective, uniform dose and route of administration of GnRH agonist and uniform luteal support combination with progesterone made comparison of the groups more reliable. Because the number of transferred embryos and Grade I embryo numbers were different between the groups, we performed subgroup analysis (Table 4, 5). By these analyses, we aimed to alleviate the confounding heterogeneity between the groups with respect to the number of both transferred embryos and Grade I embryos. After stratification of cycles, we ended up with the same conclusion of absence of beneficial effects of luteal GnRH agonist addition to progesterone in IVF cycles with respect to pregnancy outcome measures (Table 4, 5).

Another remarkable result was the significantly increased multiple pregnancy rates in antagonist cycles with GnRH agonist addition. However, this result was not observed in long agonist cycles with GnRH agonist arm in our study (Table 3). Increase in multiple pregnancies was observed in the studies of Tesarik et al. (14), Isik et al. (22), Ylddz et al. (25). It can be speculated that
Table 5. Live Birth Rates according to the transfer of number of grade 1 embryo

\begin{tabular}{|l|l|c|c|c|}
\hline \multirow{2}{*}{ Number of grade I embryo } & Group A & Group B & $\begin{array}{c}\text { p } \\
\text { value }\end{array}$ \\
\hline $\begin{array}{l}\text { 1 Grade I embryo, } \\
\text { n (\%) }\end{array}$ & Long agonist & $208(37.1)$ & $86(35.8)$ & 0.75 \\
\cline { 2 - 5 } & Antagonist & $162(32.0)$ & $88(32.4)$ & 0.94 \\
\hline $\begin{array}{l}\text { 2 Grade I embryos, } \\
\text { n (\%) }\end{array}$ & Long agonist & $141(41.2)$ & $70(44.9)$ & 0.49 \\
\cline { 2 - 5 } & Antagonist & $49(35.3)$ & $20(39.2)$ & 0.61 \\
\hline $\begin{array}{l}3 \text { or more grade I } \\
\text { embryos, n (\%) }\end{array}$ & Long agonist & $120(48.8)$ & $74(45.7)$ & 0.54 \\
\cline { 2 - 5 } & Antagonist & $19(44.7)$ & $6(56.8)$ & 0.16 \\
\hline $\begin{array}{l}\text { Group A: GnRH agonist+progesterone luteal support, Group B: Progesterone only } \\
\text { luteal support. }\end{array}$ \\
\hline
\end{tabular}

GnRH agonist addition may increase multiple pregnancy rates either by direct effect on embryo implantation via GnRH receptors present on the endometrium or by the receptors present on the embryo. However, any effect of this kind awaits verification in further studies with selective single embryo transfer cycles.

After initial clinical randomized trials with beneficial effects, we used GnRH agonist as a luteal adjunct in long agonist and antagonist stimulation IVF cycles relatively liberally in our IVF clinic. Absence of anticipated increase in live birth rates led us to cease routine $\mathrm{GnRH}$ agonist addition to progesterone in our clinic. Therefore, we reached the highest numbers of $\mathrm{GnRH}$ agonist administered cycles. Although retrospective in nature, this study constitutes the largest study on the effect of GnRH agonist addition to luteal support in IVF cycles. Predetermined fixed dose of GnRH agonist administration and standard luteal phase support with progesterone strengthen our data for more uniform analysis. However, there are limitations to our analysis: retrospective nature and uncontrollable patient and cycle characteristics preclude drawing firm conclusions. Although we tried to eliminate many confounding variables with strict inclusion criteria, there are still some other factors such as longevity of study with different culture mediums and different infertility reasons that may affect pregnancy outcome measures.

Although there are considerable studies on literature, beneficial effects on pregnancy outcome measures were highly blurred by the lack of uniform administration of $\mathrm{GnRH}$ agonist in regard to effective dose, administration period, and absence of ideal combination with which GnRH agonist combines with other luteal phase supporting agent or agents (i.e., progesterone, estradiol, hCG).

In conclusion, our study failed to demonstrate any benefit of addition of single $0.1 \mathrm{mg}$ dose of luteal $\mathrm{GnRH}$ analog (triptorelin) to the routine luteal phase support with progesterone in IVF cycles on live birth rates. The mechanisms of actions and the ideal dose, administration route, and time interval of $\mathrm{GnRH}$ agonist administration in the luteal phase support remain largely undetermined. Presumptive beneficial effect, if any, may only be uncovered after carefully designed preclinical studies and well-designed randomized clinical studies with different dose regimens and administration routes. In the light of current literature and our findings, routine administration of single-dose GnRH agonist as a beneficial luteal phase adjunct in IVF cycles 
cannot be recommended until after future randomized studies prove the beneficial effects.

Ethics Committee Approval: Ethics committee approval was received for this study from the ethics committee of Baskent University (project number: KA 12/57).

Informed Consent: $N / A$

Peer-review: Externally peer-reviewed.

Author Contributions: Concept - E.S.., E.B.K.; Design - E.B.K., E.S., S.Y.S.; Supervision - E.B.K., B.H.; Resource - E.Sु., E.B.K; Materials - E.Ş., G.Ç., T.Ç.; Data Collection \&/or Processing - E.S., P.Ç.A., B.H.; Analysis \&/or Interpretation E.S., E.B.K., S.Y.S.., G.Ç.; Literature Search - E.S., S.Y.S., B.H; Writing - E.S., S.Y.S., G.Ç.; Critical Reviews - E.B.K., S.Y.Ş., G.Ç., P.Ç.A.

Conflict of Interest: No conflict of interest was declared by the authors.

Financial Disclosure: The authors declared that this study has received no financial support.

\section{References}

1. DiLuigi AJ, Nulsen JC. Effects of gonadotropin-releasing hormone agonists and antagonists on luteal function. Curr Opin Obstet Gynecol 2007; 19: 258-65. [CrossRef]

2. Macklon NS, Fauser BC. Impact of ovarian hyperstimulation on the luteal phase. J Reprod Fertil Suppl 2000; 55: 101-8.

3. Kolibianakis EM, Albano C, Kahn J, Camus M, Tournaye H, Van Steirteghem AC, Devroey P. Exposure to high levels of luteinizing hormone and estradiol in the early follicular phase of gonadotropinreleasing hormone antagonist cycles is associated with a reduced chance of pregnancy. Fertil Steril 2003; 79: 873-80. [CrossRef]

4. Tavaniotou A, Smitz J, Bourgain C, Devroey P. Ovulation induction disrupts luteal phase function. Ann N Y Acad Sci 2001; 943: 55-63. [CrossRef]

5. Tavaniotou A, Albano C, Smitz J, Devroey P. Impact of ovarian stimulation on corpus luteum function and embryonic implantation. J Reprod Immunol 2002; 55: 123-30. [CrossRef]

6. Ata B, Yakin K, Balaban B, Urman B. GnRH agonist protocol administration in the luteal phase in ICSI-ET cycles stimulated with the long GnRH agonist protocol: a randomized, controlled double blind study. Hum Reprod 2008; 23: 668-73. [CrossRef]

7. Pritts EA, Atwood AK. Luteal phase support in infertility treatment: a meta-analysis of the randomized trials. Hum Reprod 2002; 17: 2287-99. [CrossRef]

8. Fauser BC, Devroey P. Reproductive biology and IVF: ovarian stimulation and luteal phase consequences. Trends Endocrinol Metab 2003; 14: 236-42. [CrossRef]

9. Munoz E, Taboas E, Portela S, Aguilar J, Fernandez I, Munoz L, Bosch E. Treatment of luteal phase defects in assisted reproduction. Curr Drug Targets 2013; 14: 832-42. [CrossRef]

10. Aboulghar M. Luteal support in reproduction: when, what and how? Curr Opin Obstet Gynecol 2009; 21: 279-84. [CrossRef]

11. Hubayter ZR, Muasher SJ. Luteal supplementation in in vitro fertilization: more questions than answers. Fertil Steril 2008; 89: 749-58. [CrossRef]

12. van der Linden M, Buckingham K, Farquhar C, Kremer JA, Metwally M. Luteal phase support for assisted reproduction cycles. Cochrane Database Syst Rev 2011; CD009154.

13. Pirard C, Donnez J, Loumaye E. GnRH agonist as luteal phase support in assisted reproduction technique cycles: results of a pilot study. Hum Reprod 2006; 21: 1894-900. [CrossRef]
14. Tesarik J, Hazout A, Mendoza-Tesarik R, Mendoza N, Mendoza C. Beneficial effect of luteal-phase GnRH agonist administration on embryo implantation after ICSI in both GnRH agonist- and antagonist-treated ovarian stimulation cycles. Hum Reprod 2006; 21: 2572-9. [CrossRef]

15. Skarin G, Nillius SJ, Wide L. Failure to induce early abortion by huge doses of a superactive LRH agonist in women. Contraception 1982; 26: 457-63. [CrossRef]

16. Gartner B, Moreno C, Marinaro A, Remohi J, Simon C, Pellicer A. Accidental exposure to daily long-acting gonadotrophin-releasing hormone analogue administration and pregnancy in an in-vitro fertilization cycle. Hum Reprod 1997; 12: 2557-9. [CrossRef]

17. Kol S, Lightman A, Hillensjo T, Devroey P, Fauser B, Tarlatzis B, et al. High doses of gonadotrophin-releasing hormone antagonist in invitro fertilization cycles do not adversely affect the outcome of subsequent freeze-thaw cycles. Hum Reprod 1999; 14: 2242-4. [CrossRef]

18. Golan A, Ron-el R, Herman A, Weinraub Z, Soffer Y, Caspi E. Fetal outcome following inadvertant administration of long-acting DTRP6 GnRH microcapsules during pregnancy: a case report. Hum Reprod 1990; 5: 123-4.

19. Elefant E, Biour B, Blumberg-Tick J, Roux C, Thomas F. Administration of a gonadotropin-releasing hormone agonist during pregnancy: follow-up of 28 pregnancies exposed to triptoreline. Fertil Steril 1995; 63: 1111-3.

20. Pirard C, Donnez J, Loumaye E. GnRH agonist as novel luteal support: results of a randomized, parallel group, feasibility study using intranasal administration of buserelin. Hum Reprod 2005; 20: 1798-804. [CrossRef]

21. Tesarik J, Hazout A, Mendoza C. Enhancement of embryo developmental potential by a single administration of $\mathrm{GnRH}$ agonist at the time of implantation. Hum Reprod 2004; 19: 1176-80. [CrossRef]

22. Isik AZ, Caglar GS, Sozen E, Akarsu C, Tuncay G, Ozbicer T, Vicdan K. Single-dose GnRH agonist administration in the luteal phase of GnRH antagonist cycles: a prospective randomized study. Reprod Biomed Online 2009; 19: 472-7. [CrossRef]

23. Ata B, Urman B. Single dose GnRH agonist administration in the luteal phase of assisted reproduction cycles: is the effect dependent on the type of GnRH analogue used for pituitary suppression? Reprod Biomed Online 2010; 20: 165-6; author reply 7. [CrossRef]

24. Isikoglu M, Ozgur K, Oehninger S. Extension of GnRH agonist through the luteal phase to improve the outcome of intracytoplasmic sperm injection. J Reprod Med 2007; 52: 639-44.

25. Yıldız GA, Şükür YE, Ateş C, Aytaç R. The addition of gonadotrophin releasing hormone agonist to routine luteal phase support in intracytoplasmic sperm injection and embryo transfer cycles: a randomized clinical trial. Eur J Obstet Gynecol Reprod Biol 2014; 182: 66-70. [CrossRef]

26. Oliveira JB, Baruffi R, Petersen CG, Mauri AL, Cavagna M, Franco JG Jr. Administration of single-dose GnRH agonist in the luteal phase in ICSI cycles: a meta-analysis. Reprod Biol Endocrinol 2010; 8: 107. [CrossRef]

27. Kyrou D, Kolibianakis EM, Fatemi HM, Tarlatzi TB, Devroey P, Tarlatzis BC. Increased live birth rates with GnRH agonist addition for luteal support in ICSI/IVF cycles: a systematic review and metaanalysis. Hum Reprod Update 2011; 17: 734-40. [CrossRef]

28. Isikoglu M, Ozgur K, Oehninger S. Extension of GnRH agonist through the luteal phase to improve the outcome of intracytoplasmic sperm injection. J Reprod Med 2007; 52: 639-44.

29. Razieh DF, Maryam AR, Nasim T. Beneficial effect of lutealphase gonadotropin-releasing hormone agonist administration on implantation rate after intracytoplasmic sperm injection. Taiwan J Obstet Gynecol 2009; 48: 245-8. [CrossRef]

30. Fujii S, Sato S, Fukui A, Kimura H, Kasai G, Saito Y. Continuous administration of gonadotrophin-releasing hormone agonist during the luteal phase in IVF. Hum Reprod 2001; 16: 1671-5. [CrossRef] 